\title{
Mediating Effects of Antisocial Peer Conformity on the Relationship between External Resilience and Social Isolation among School Dropout Adolescents
}

\author{
Chang-kyoung Kang ${ }^{1}$, Chang-hoon $\mathrm{Seog}^{2}$, Young-min Park ${ }^{3}$ \\ ${ }^{1}$ Research Professor, Student Counseling Center, SunMoon University, Korea, \\ k-changkyoung@daum.net \\ ${ }^{2}$ Professor, College of Liberal Arts, SunMoon University, Korea, chseog@sunmoon.ac.kr \\ ${ }^{3}$ Professor, Division of Convergence, Sookmyung Woman University, Korea, \\ ympillow@sookmyung.ac.kr \\ Corresponding author: Chang-hoon Seog
}

\begin{abstract}
The purpose of this study is to verify the mediating effects of anti-social peer conformity on the relationship between external resilience and social isolation among school dropout during adolescence. The 395 adolescent school dropouts were surveyed using youth resilience, peer conformity and loneliness scales. They came from Gangwon (16), Gyeonggi (55), Gyeongnam (28), Gyeongbuk (65), Gwangju (6), Daegu (33), Daejeon (11), Busan (19), Seoul (46), Ulsan (9), Incheon (32), Jeonnam (14), Jeonbuk (11), Chungnam (28), and Chungbuk (22). The data collection ran through a postal survey from July 15 to August 15, 2021. A total of 1500 questionnaires of 218 Dream Centers were distributed to the respondents, where 395 were counted as valid. The related procedure was conducted with the cooperation of teachers in charge of institutions that educate the out-of-school youth. The instruments used in the study were External Resilience Scale, Antisocial Peer Conformity Scale, and Scale of Social Isolation. The data analysis was performed using SPSS 25.0. The results of the study are as follows. First, it was found that the external resilience of school dropout during adolescence had a negative correlation with social isolation and anti-social peer conformity. Second, the anti-social peer conformity had partial mediating effects on the relation between external resilience and social isolation of school dropout during adolescence. Third, among the external resilience of school dropout during adolescence, the influence of their peers' support system are the highest. This study is meaningful that it validates the mutual influence of the three factors(external individual, individual-environment, internal individual) associated with school dropout phenomenon.
\end{abstract}

Keywords: School Dropout, External Resilience, Social Isolation, Anti-Social Peer Conformity

\section{Introduction}

\subsection{Need for Study}

In order to improve the image of derailment or fallout, which means dropout in relation to adolescents' school dropout, the 2003 Youth Basic Act officially uses the term 'school dropout adolescents' and defined the meaning of school interruption as a phenomenon in which multiple factors exist in adolescents, families, schools, and society[1].

Received: April 21, 2021; $1^{\text {st }}$ Review Result: June 5, 2021; $2^{\text {nd }}$ Review Result: July 23, 2021

Accepted: August 30, 2021 
However, in a strict sense, school dropout adolescents refer to students who stopped studying in the middle of high school education that does not fall under the category of compulsory education due to dropout (disease, housework, maladjustment, overseas departure, etc.), expulsion(conduct), exclusion, postponement, exemption in the case of compulsory elementary and middle schools, postponement (illness, long-term absence, unrecognized study abroad) and exemption (disease, overseas departure) are applicable.

According to the Ministry of Education statistics[2], the characteristics of the school dropout adolescents estimates for the last 10 years is that the dropout rate in high school is higher than that of elementary and middle schools. The high school dropout rate in 2019 was 1.7 percent, roughly more than twice that of 0.7 percent in elementary schools and 0.8 percent in middle schools. In addition, the elementary, middle and high school dropout rate has generally decreased from 2010 to 2015 but is showing an increasing trend again from 2015. The number of students who stopped studying in elementary, middle, and high schools in the last three years was 47,663 in 2016, 50,057 in 2017, and 52,539 in 2018, and more than 150,000 students have left the public education field for three years.

The phenomenon of school dropout in adolescent period is the result of various factors. According to the analysis of Lee Jeong-suk's previous research[3], school dropout and personal factors such as selfesteem, self-resilience, self-efficacy, depression, and delinquency, family factors such as parenting attitude and family environment, school factors such as poor learning, school violence, and maladjustment to the school system, conflicts with teachers and peers, and relational elements such as support systems are presented.

As such, despite the combination of factors involved in school dropout, researchers in the field of contents have focused on typical characteristics-delinquency, satisfaction, and college student-centered and identified them as a result of social, economic, and educational disadvantages. Recently, however, the ecosystem of school dropout adolescents has diversified. The middle class is increasing as the socalled new generation of school dropout adolescents, and social and psychological factors are more highlighted, such as voluntarily choosing to stop studying.

Kim Bum-gu and Jo-Ami[4], who studied the types and socio-psychological characteristics of school dropout adolescents presented self-regulation, self-efficacy, career maturity, parental attitude, social support, and expectations for the future as the characteristic variables of the school-dropout adolescents The Korea Institute of Social Research, which studied the social psychology and deviant behavior of Korean adolescents, set the self-evaluation (self-evaluation self-esteem) and psychological anxiety (social isolation, experimental anxiety, stress, and worry) as social psychological factors, and analyzed the relationship between deviant behavior and school violence[5].

In the study of overseas studies related to socio psychological factors of school dropout adolescents, Fall and Roberts[6] attempted to analyze the interactions of social context, self-perception, and school participation in relation to school dropout in the United States high school, and to take a social psychological approach that affects the school dropout by deriving the Self-System Model of Motivational Development (SSMMD). Fall and Roberts presented parents' support and teacher's support in social context, school recognition and control recognition in self-perception, and behavioral participation, academic participation, and academic achievement variables in school participation. The characteristics of this model are that the school dropout phenomenon is analyzed directly and indirectly on the factors of the process.

In addition, a study by Awang-Hashim[7] of 2,311 middle and high school students (1,119 males and 1,262 females) from 40 schools across Malaysia confirmed static correlation between life satisfaction, emotion, meaning of life and resilience as social psychological factors of school participation. However, in Korea, about $41.6 \%$ of out-of-school youths are transferred to NEET (Not in Education, Employment or Training; NEET), and if left unattended, it is likely to cause various social problems such as game addiction, seclusion, delinquency, youth unemployment, and it is considered that there is a risk of 
weakening national competitiveness in the future[8]. However, most of the existing studies of out-ofschool adolescents have limitations that internalize social negative views of them, assuming they are problematic or juvenile delinquents. Recently, some studies have described the fact that there are many teenagers who successfully adapt to our society, such as continuing to learn or succeeding in finding a job after dropping out of school[9]. In other words, it is important for out-of-school adolescents to make continuous efforts to achieve the established plan as much as to find their own career path and plan for the future. For these efforts, strong motivation is required to endure difficulties and achieve plans[10]. Thus, by actively accepting and developing these recent research trends, this study is to explore the main variables that affect psychological and social well-being, social adaptation and self-reliance of out-ofschool adolescents based on the theory of Positive Psychology (Seligman, 1999) and to clarify the direct and indirect influence relationship between the main variables.

Therefore, this study is aimed to analyze the phenomenon of school dropout in depth through social psychological approaches to school dropout, and to explore the direction of educational policies to prevent school dropout.

\subsection{Questions}

This study seeks to understand the educational policy implications by focusing on individual internal variables (social isolation), individual environmental variables (peer conformity), and individual external variables (resilience) based on the previous studies in order to supplement the social psychological approach to the school-dropout adolescents and to analyze the phenomenon of dropout in depth. To achieve this purpose, the following research questions were set up.

First, what is the relationship among external resilience, antisocial peer conformity, and social isolation of school-dropout adolescents?

Second, what is the mediating effect of antisocial peer conformity in the relationship between external resilience and social isolation of school-dropout adolescents?

Third, which factors of sub-protection factors of external resilience of school-dropout adolescents have the greatest effect?

\section{Literature Review}

\subsection{Adolescent's School Dropout Factor}

The causes of adolescents' dropout of regular schooling are complex and often result in various problems. Yoon Yeogak and others classified the causes of the school dropout in relation to the types of school dropout[11]. It is reported that dissatisfaction with family, burden of livelihood, dissatisfaction with school, difficulty in studying the subject, serious violation of school rules, deterioration of health, early study abroad or immigration affect each other and lead to school dropout.

In other words, one factor does not affect the school dropout, but various factors create problem behaviors and cultures, which affect the decision to stop studying. It also suggests that runaway or serious violation of school rules can be a decisive factor in delinquency or school dropout.

This seems to be a model that explains the school dropout of delinquent adolescents, but it is difficult to explain the reason for school dropout of all adolescents. However, it is useful to explain the process of various factors having a complex effect on each other, being expressed as problematic behavior and leading to school dropout.

In addition, many previous studies have analyzed and explained the factors of school dropout. In relation to the factors of school dropout, Koo Bon-yong and Yoo Je-min[12] explained that there were more than 150 variables, which means that the factors related to school dropout are complex and 
multilayered.

In order to help predict students who are likely to discontinue their studies in advance so that they can graduate from the middle and high school curriculum, while analyzing the causes and factors of school dropout to verify the causal model, Bae Young-tae analyzed the causes of school dropout by dividing it into individual, family, school, peer relationship, and community factors. First of all, in the personal factors, emotional problems such as lack of academic achievement ability and motivation, depression, helplessness, and anxiety about future career were presented as the problem of academic maladjustment. Family factors are related to the family environment and family relationship factors, such as the family's social and economic status, parents' unemployment, lack of financial support, and dismantling of family members due to parental conflicts. School factors are classified into factors related to the school system or school characteristics, students' attitude toward school, and problems of school life. The peer relationship factors are the factors that arise from relationships with the peers, such as alienation from school, contact with the school dropout adolescents, and unsound relationships with the opposite sex. Community factors were explained as harmful environment, residence in crime zone, lack of social support, etc., which could have direct or indirect influence on the school dropout[13].

In conclusion, the study can be classified into four categories by linking the factors of school dropout with maladjustment factors.

The first is the academic factors. There are maladjustment factors such as poor grades, lack of academic ability, inability to withstand structured activities of schools, low job aspirations compared to peers, abstract thinking, generalization, difficulty in forming relationships, and lack of basic mathematical skills.

The second is the behavioral factors. There are maladjustment factors such as high truancy and longterm absence rate, lack of special activity, frequent health problems, a lot of impulsive decision making, drug abuse, delinquency, and attempted suicide.

The third is the family factors. There are maladjustment factors such as single-parent families, low income families, low ties with family, frequent moving, lack of cultural experience related to success in traditional school programs, etc.

The fourth is the psychological factors. These include feeling rejected at school, negative attitude toward school, lack of motivation for achievement in school life, socially isolated, emotionally insecure, lack of self-concept, lack of a clear identity, deep wounds such as abused experiences in the mind, inability to connect themselves to authoritative figures, and feeling attractive to earning-money or social life experiences.

In short, the factors of school dropout are the interaction between individual, external, and individual and environment, which are combined with various adaptation or maladjustment factors.

\subsection{Social Psychological Variables of School Dropout Adolescents}

\subsubsection{Individual External Variables: External Resilience}

Resilience plays an important role in improving the quality of life as a human psychological and social ability to promote adaptation and reduce negative emotions in adversity[14]. In the case of adolescents, there are individual differences in development and adaptation, but they often face negative paths.

Despite the crisis, it is necessary to pay attention to the ability to overcome or cope with difficult situations, that is, the resilience of adolescents. In the domestic meta-analysis study related to resilience of adolescents, Jung Eun-joo and Jung Kyung-eun meta-analyzed 233 papers related to resilience of adolescents published in Korea for 18 years from 1998 to 2016[15]. Individual psychological variables (sociality, initiative, interpersonal relationship, self-efficacy, positive emotion, internal traits, vitality, responsibility, optimism), family variables (family area, family support), school variables (school adjustment, peer relationship), social variables (social support) were found to have effects as a triggering 
variable that promotes resilience of adolescents, while personal psychological variables (health problems, aggression, suicide, interpersonal problems, stress, addiction), and family variables (negative parenting and protection) were analyzed to be effective as inhibitory variables.

However, the domestic resilience study mainly defines and measures only as individual personality traits or only measures to stay in the family-level protection factors, so the important school and community protection factors for adolescents are overlooked. In this regard, Lee Hae-ri and Cho Han$\mathrm{ik}$ divided the resilience factors of adolescents into individual internal factors and external protection factors, and classified the internal factors into cognitive, emotional, willful, and spiritual dimensions. External protection factors were classified into school, family, community, and peer dimensions[16]. Among them, external protective factors form the central axis of the educational ecosystem surrounding school dropout adolescents.

The factors and concepts related to the external resilience of adolescents are summarized as shown in [Table 1]. This study on the resilience of adolescents has a significant meaning in the prevention, educational and therapeutic dimensions of adolescent problems through understanding and diagnosis of adolescents who are experiencing adaptive difficulties.

[Table 1] Adolescents' External Resilience Factors and Concept Definition

\begin{tabular}{|c|c|c|}
\hline \multicolumn{2}{|r|}{ Division } & Definition \\
\hline \multirow{2}{*}{$\begin{array}{c}\text { School } \\
\text { dimension }\end{array}$} & Relationship and Expectation of Care & $\begin{array}{l}\text { Teachers' interest, support, encouragement and expectation as } \\
\text { positive experiences that can be experienced in school }\end{array}$ \\
\hline & Meaningful interaction & $\begin{array}{c}\text { Interactions such as participation in school activities such as classes } \\
\text { and class meetings }\end{array}$ \\
\hline \multirow{2}{*}{$\begin{array}{c}\text { Family } \\
\text { dimension }\end{array}$} & Relationship and Expectation of Care & $\begin{array}{c}\text { Parental warmth, encouragement, support and care, supportive } \\
\text { relationship between couples, and attitude to acknowledge faith in } \\
\text { children, talent and hobbies }\end{array}$ \\
\hline & Meaningful interaction & Family conversations and active participation in family activities \\
\hline \multirow{2}{*}{$\begin{array}{l}\text { Community } \\
\text { dimension }\end{array}$} & Relationship and Expectation of Care & $\begin{array}{l}\text { Supportive social structures such as youth welfare centers, and } \\
\text { neighbors, mentors, churches, etc. }\end{array}$ \\
\hline & Meaningful interaction & $\begin{array}{l}\text { Altruistic Behavior and Social Responsibility Improvement for } \\
\text { Self-Esteem and Competence of Adolescents }\end{array}$ \\
\hline \multirow{2}{*}{$\begin{array}{c}\text { Peer } \\
\text { dimension }\end{array}$} & Relationship and Expectation of Care & Healthy peer group acceptance, prosocial involvement and behavior \\
\hline & Meaningful interaction & Friendly and supportive interaction activities with pro-social peers \\
\hline
\end{tabular}

\subsubsection{Individual-Environmental Variables: Antisocial Peer Conformity}

Adolescence is a time to expand oneself and establish self-identity through various interactions with peers, so it is more dependent on peers than ever before and sensitive to collective thinking. Peer belongs to a similar age and social position and means an object that interacts with common interests. Peer provides social support and stability to adolescents and plays an important role in developing social functions in adolescence[17].

Peer conformity can be defined as behavior tendency to choose the behavior pattern allowed by peer group to belong to peer group even when the value and behavior of peer group are not the same as individual belief.

Although peer conformity of adolescents may be a positive factor that has an important influence on the developmental tasks of adolescents, adolescents whose values are confused and whose judgment criteria are unclear may have negative effects such as deviant behavior, bullying, Internet or drug addiction due to peer conformity[18].

The peer conformity of adolescents can be examined by two types - neutral peer conformity and 
antisocial peer conformity. Neutral peer conformity is not harmful in life, and shows a tendency to agree with peers when they talk about what they want. In other words, it is a tendency of peer conformity to positive or neutral activities. Neutral peer conformity can also be a positive factor that increases the efficiency of decision making and expands emotional ties to strengthen peer group cohesion. On the other hand, antisocial peer conformity means that peer conformity with the behavior that they are reluctant to perform, such as abusive language, theft, and delinquency, that can cause damage to others or violate the rules, and shows peer conformity to negative behaviors. In other words, antisocial peer conformity, unlike neutral peer conformity, has moral value judgments and can reinforce negative behavior[19].

Antisocial peer conformity is indiscriminately sympathetic to peer groups and is likely to be expressed in a negative direction that acts as a will of peer groups, unlike their own values and wills, by acting as a silent pressure. This can cause problems in acquiring desirable social skills or negatively affect the formation of self-identity, especially if they have strong dependence on peer groups or are young people whose values have not yet been established properly.

Therefore, it can be predicted that antisocial peer conformity can be a more negative factor compared to neutral peer conformity in the school dropout situation.

\subsubsection{Individual Internal Variables: Social Isolation}

Human beings are social beings, but they experience social isolation that is alienated from social relations. Social isolation also means an objective state with little contact with others, and is related to the emotion of loneliness, which is a negative emotion of an individual. In other words, social isolation is caused by the lack of network and the lack of interaction in various relationships in society, which can be defined as a maladjusted psychological state such as solitude and loneliness that can be felt by this.

Social isolation experienced during adolescence can be examined in personal, family, and social factors. First, as personal factors, personal characteristics such as name, gender, appearance, and school transfer rate, opportunities to participate in student activities, and experiences of success and failure affect individual isolation. Second, as family factors, factors such as neglected parenting attitude of parents or unsupportive family environment can be cited. Third, as a social factor, there is a lack of social skills. Isolated students lack a way to participate in groups, how to attract peers' attention, and social functions that respond appropriately to the interests of others. It is often ignored, rejected, shrunk, or isolated within peer groups.

O'Connor said that the characteristics of isolated children's behavior are related to the characteristics of social skills, and isolated children often do not have various social skills in the study of correlation between isolated children and social skills, which are sub-variables of social problem solving ability. According to the study on social isolation and interpersonal problem solving ability, adolescents who have good communication with their peers and have a trustworthy friendship choose appropriate coping methods according to the situation along with planned and active attempts to solve the problem in stress situations[20]. Therefore, it can be confirmed that the degree of social isolation experienced in adolescence is an important variable that plays an important role in forming a social human network for adolescents to grow into adults.

\section{Methods}

\subsection{Participants}

The data collection of this study was conducted through postal survey from July 15 to August 15, 2020. Due to the COVID-19 virus, the operation of out-of-school youth education institutions (Dream Center) was not normalized (closed), so there were many difficulties and limitations in securing the 
target of sampling, and special attention was also needed to respond, such as a sensitive response to the questionnaire. For precautionary meausres regarding the survey, the contents of the response are strictly guaranteed by Article 13 of the Statistical Act, the survey notes were faithful to the research ethics by seeking consent for personal information by revealing that they were not used for anything other than research purposes under Article 2 of the Privacy Act.

After seeking the cooperation (report) of teachers in charge of institutions that educate students who have stopped studying, which is the subject of this study, the purpose of this study and the significance related to the survey were guided. An average of 6 to 10 questionnaires (a total of 1,500 copies) were distributed to 218 Dream Centers nationwide, of these, 413 were collected, showing a $27.5 \%$ collection rate. After that, 395 data were finally collected except for 18 data that showed no response, insincere response, and outlier response in the data analysis stage. The effective data rate was $95.6 \%$. The demographic characteristics of the 395 students who stopped studying nationwide- gender, age group, time of school dropout, period of school dropout, grades at the time of dropout, type of school dropoutare as shown in [Table 2].

[Table 2] Demographic Characteristics of School Dropout Adolescents

\begin{tabular}{|c|c|c|c|}
\hline \multicolumn{2}{|c|}{ Division } & Respondent & Ratio(\%) \\
\hline \multirow{2}{*}{ Gender } & Male & 139 & 35.2 \\
\hline & Female & 256 & 64.8 \\
\hline \multirow{3}{*}{ Age } & $13 \sim 15$ & 43 & 10.8 \\
\hline & $16 \sim 18$ & 270 & 68.4 \\
\hline & 19 24 & 82 & 20.8 \\
\hline \multirow{7}{*}{ Time of school dropout } & Elementary & 10 & 2.5 \\
\hline & Middle school $1 \mathrm{G}$ & 24 & 6.1 \\
\hline & Middle school 2G & 21 & 5.3 \\
\hline & Middle school 3G & 29 & 7.3 \\
\hline & High school $1 \mathrm{G}$ & 196 & 49.6 \\
\hline & High school 2G & 94 & 23.8 \\
\hline & High school 2G & 21 & 5.3 \\
\hline \multirow{5}{*}{ Period of school dropout } & Less than a year & 144 & 36.5 \\
\hline & Less than one or two years & 131 & 33.1 \\
\hline & Less than two or three years & 61 & 15.4 \\
\hline & Less than three or four years & 28 & 7.1 \\
\hline & More than four years & 31 & 7.9 \\
\hline \multirow{5}{*}{ Grades at the time of dropout } & Top-level & 32 & 8.1 \\
\hline & Middle-high & 69 & 17.5 \\
\hline & Mid-level & 116 & 29.4 \\
\hline & Mid-low-level & 119 & 30.1 \\
\hline & Low-level & 59 & 14.9 \\
\hline \multirow{5}{*}{ Type of school dropout } & Postponement & 29 & 7.3 \\
\hline & Exemption & 2 & 0.5 \\
\hline & Dropout & 347 & 87.8 \\
\hline & Expulsion & 10 & 2.5 \\
\hline & Exclusion & 7 & 1.8 \\
\hline \multicolumn{2}{|c|}{ Total } & 395 & 100.0 \\
\hline
\end{tabular}

\subsection{Research Tools and Procedures}

In this study, a questionnaire consisting of 50 questions in four areas, which are the characteristics of 
respondents, external resilience, peer conformity, and social isolation, was used to identify the relationship between external resilience, antisocial peer conformity, and social isolation of school dropout adolescents.

Before conducting the survey, the process of verifying the content validity, the construct validity, and the reliability of the survey tool was conducted. In order to examine whether the contents of the survey tool are appropriate, the content validity was verified by three professors majoring in education. In order to examine whether the contents of the survey tool were easily understood, the clarity of the instructions and the ease of reading and response were verified by six middle and high school students and two teachers.

\subsubsection{External Resilience Scale}

In this study, 'Resilience Scale of Korean Adolescents' developed by Lee Hae-ri and Cho Han-ik was used to measure the level of external protective variables among resilience of school-dropout adolescents. In this scale, 24 questions were included in four dimensions: school level, family level, community level, and peer level. The questions of this scale are evaluated as six-point Likert scale, and the higher the total score, the higher the level of resilience. In the study of Lee Hae-ri and Cho Han-ik, internal consistency(Cronbach's $\alpha$ ) was .94 for total, distributed between .96 and .62. In this study, internal consistency of the external resilience scale was .88 for family, .80 for school, .79 for community, .85 for peer, and .91 for total.

\subsubsection{Antisocial Peer Conformity Scale}

To measure antisocial peer conformity, the peer conformity scale developed by Kim Eun-jin and modified by Lee Bok-hee's terminology was used. The peer conformity scale consists of two sub-types, eight items in neutral conformity, and eight items in antisocial conformity. However, considering that neutral peer conformity has a weak relationship with adolescent problem behaviors such as peer bullying and can have a positive effect on peer relationships of adolescents, this study excluded neutral peer conformity among peer conformity scales and decided to use only eight items of antisocial peer conformity scale. The questions of this scale are evaluated as six-point Likert scale, and the higher the total score, the higher the degree of antisocial conformity and the more negative interpersonal relationship. In Lee Bok-hee's study, internal consistency was .76 and in this study, internal consistency was .85 .

\subsubsection{Scale of Social Isolation}

In this study, we used the Revised UCLA Loneliness Scale (RULS) developed by Russell et al. The scale consists of 10 questions, and according to the contents of the scale published by the original author, the sub-factors are used as integrated versions of the scale that are not presented separately. The questions of this scale are evaluated as a four-point Likert scale, which means that the higher the total score, the higher the level of social isolation and the negative adaptive psychological state. In Lee Jungeun's study, the internal consistency was .88 and in this study, the internal consistency was .86 .

\subsubsection{Data Collection Procedure}

Data collection was conducted through postal survey from July 15 to August 15, 2020. A total of questionnaires for the Dream Centers were distributed (a total of 1,500) and 395 data were finally collected. The related procedure was conducted with the cooperation of teachers in charge of institutions that educate the out-of-school youth. 


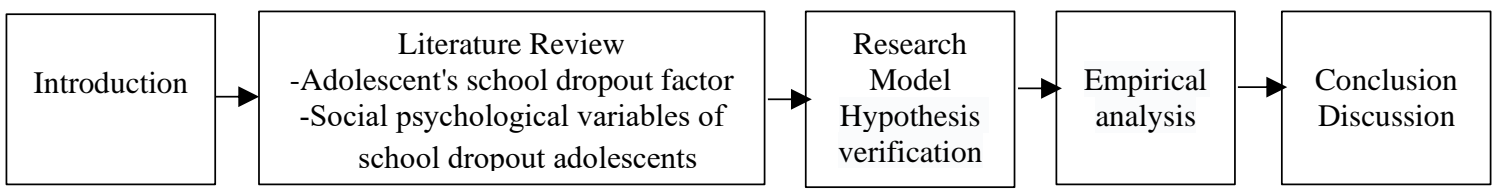

[Fig. 1] Research Procedure

\subsection{Data Analysis}

The data collected in this study were analyzed using Windows SPSS 25.0 statistical program, and the statistical significance level was set at $5 \%$ for all analysis. Descriptive statistics such as frequency, percentage, mean, and standard deviation were used as major statistical methods. Correlation analysis and Baron \& Kenny's three-step multiple regression analysis were conducted to reveal the relationship between variables and the mediating effect of the variables.

\subsection{Ethical Considerations Observed in the Conduct of the Study}

School dropout adolescents experience many factors that caused the discontinuation of their studies even after school dropout. Specifically, family conflicts, difficulties in life management, difficulties in interpersonal relationships, emotional pain, and delinquency problems are often even more deepened and expanded. In this regard, school dropout adolescents might have complex problems unlike ordinary adolescents, so it is necessary to respond sensitively and flexibly to the problems and needs of students who have stopped studying[21]. Considering the characteristics of school dropout adolescents, the researchers maintained neutrality and thorough confidentiality of the participants. In addition, the researchers completed the research ethics of the National Institute of Science and Technology Human Resources Development (KIRD) and established the ethical attitude required by the researchers to observe ethical considerations in the research performance.

\section{Results}

\subsection{External Resilience Level of School Dropout Adolescents}

As shown in [Table 3], we found the level of external resilience of school dropout adolescents was 25.36 points, which is about the average level. The dimension of peers was the highest (28.67 points), family dimension (24.72 points), school dimension (24.27 points), and community dimension (23.78 points). This means that the support system of peer group has the greatest influence among the external protection factors of school dropout adolescents.

[Table 3] Differences in External Resilience Levels of School Dropout Adolescents

\begin{tabular}{|c|c|c|c|c|c|c|}
\hline Variable & Division & M & SD & $\mathrm{f}$ & $\mathrm{p}$ & schffe \\
\hline \multirow{5}{*}{$\begin{array}{l}\text { External } \\
\text { resilience }\end{array}$} & a. Family dimension & 24.72 & 5.67 & \multirow{5}{*}{10.26} & \multirow{5}{*}{.000} & \multirow{5}{*}{$d>a, b, c$} \\
\hline & b. School dimension & 24.27 & 6.30 & & & \\
\hline & c. Community dimension & 23.78 & 6.94 & & & \\
\hline & d. Peer dimension & 28.67 & 4.94 & & & \\
\hline & Total & 25.36 & 5.96 & & & \\
\hline
\end{tabular}




\subsection{Analysis of Correlations among External Resilience, Social Isolation, and Antisocial Peer Conformity of School Dropout Adolescents}

As presented in [Table 4], the correlation between external resilience, antisocial peer conformity, and social isolation of school dropout adolescents, and social isolation showed a negative correlation with the whole external resilience of -.53 , and in detail, family factor $(\mathrm{r}=-.46)$, school factor $(\mathrm{r}=-.40)$, community factor $(\mathrm{r}=-.50)$, and peer factor $(\mathrm{r}=-.45)$ showed moderate negative correlation with the overall external resilience. On the other hand, social isolation and antisocial peer conformity showed a low but significant positive correlation of .25 . The degree of skewness and kurtosis was below \pm 2 , and the normality of the factors was confirmed, as presented in [Table 4].

[Table 4] Correlation between External Resilience, Antisocial Peer Conformity, and Social Isolation of School Dropout Adolescents

\begin{tabular}{|c|c|c|c|c|c|c|c|}
\hline Division & 1 & $1-1$ & $1-2$ & $1-3$ & $1-4$ & 2 & 3 \\
\hline 1.External resilience & - & & & & & & \\
\hline 1-1. Family factors & $.77 * *$ & - & & & & & \\
\hline 1-2. School factors & $.89 * *$ & $.49 * *$ & - & & & & \\
\hline 1-3. Community factors & $.92 * *$ & $.57 * *$ & $.87 * *$ & - & & & \\
\hline 1-4. Peer factors & $.81^{* *}$ & $.60 * *$ & $.63 * *$ & $.61 * *$ & - & & \\
\hline 2. Antisocial peer conformity & $-.47 * *$ & $-.33 * *$ & $-.43 * *$ & $-.37 * *$ & $-.49 * *$ & - & \\
\hline 3. Social isolation & $-.53 * *$ & $-.46^{* *}$ & $-.40 * *$ & $-.50 * *$ & $-.45^{* *}$ & $.25^{* *}$ & - \\
\hline 4. $\mathrm{M}$ & 25.36 & 24.72 & 24.27 & 23.78 & 28.67 & 17.51 & 16.87 \\
\hline 5. SD & 5.96 & 5.67 & 6.30 & 6.94 & 4.94 & 7.07 & 6.46 \\
\hline Skewness & -.24 & -.73 & -.27 & -.41 & -.43 & .78 & .87 \\
\hline Kurtosis & -.42 & -.10 & -.26 & -.49 & -.43 & -.03 & .12 \\
\hline
\end{tabular}

$* * \mathrm{P}<0.01$

\subsection{Mediating Effects of Antisocial Peer Conformity on the Relationship between External Resilience and Social Isolation of School Dropout Adolescents}

In order to verify the mediating effect of antisocial peer conformity on the relationship between external resilience and social isolation of school dropout adolescents, the analysis was conducted based on Baron and Kenny's model. The results of examining the multicollinearity and Durbin-Watson coefficients between independent variables before multiple regression analysis showed that the Variance Inflation Factor (VIF) was below five, and there was no problem with multicollinearity, and the DurbinWatson coefficient was close to two, so there was no correlation between residuals, thus it was confirmed that there was no problem in the regression analysis.

The following[Table 5] is the result of verifying the mediating effect of antisocial peer conformity on the relationship between external resilience and social isolation of the school dropout adolescents. In the first stage, external resilience, which is an independent variable, has a significant negative effect on antisocial peer conformity $(\beta=-.47, \mathrm{p}<0.01)$. 
In the second stage, external resilience, which is an independent variable, was shown to have a significant negative effect on social isolation $(\beta=-.53, p<0.01)$, a dependent variable.

In the third stage, as a result of simultaneously introducing the independent variable, external resilience, and the mediating variable, antisocial peer conformity, the independent variable, resilience $(\beta=-.07 \mathrm{p}<0.01)$ and the mediating variable, peer conformity $(\beta=-.48, \mathrm{p}<0.01)$ were found to have significant negative effects on social isolation, but the effects were decreased compared to the second stage $(\beta=-.53 \rightarrow-.07)$. In addition, it can be seen that the explanatory power of the third $\operatorname{step}\left(\mathrm{R}^{2}=.34\right)$ is increased compared to the explanatory power of the second $\operatorname{step}\left(\mathrm{R}^{2}=.21\right)$.

The results of Sobel Test also showed that the mediating effect was statistically significant $(\mathrm{z}=-3.21$, $\mathrm{p}<.001)$. These results showed that antisocial peer conformity was significant in both mediating effect and independent variable in the relationship between external resilience and social isolation of school dropout adolescents, and that the regression coefficient value of independent variable decreased in three stages than two stages, and that it had a partial mediating effect.

[Table 5] Mediating Effects of Antisocial Peer Conformity on the Relationship between External Resilience and Social Isolation of School Dropout Adolescents

\begin{tabular}{|c|c|c|c|c|c|}
\hline \multirow{2}{*}{ Independent variable } & \multicolumn{3}{|c|}{ Social isolation } & \multirow{2}{*}{ VIF } & \multirow{2}{*}{$\begin{array}{c}\text { Durbin- } \\
\text { Watson }\end{array}$} \\
\cline { 2 - 5 } & $\beta$ & $\mathrm{t}$ & $\mathrm{R} 2$ & & 1.91 \\
\hline Stage 1 External resilience & $-.47^{* *}$ & -10.56 & .24 & 1.00 & 1.87 \\
\hline Stage 2 & $-.53^{* *}$ & -12.48 & .21 & 1.00 & \multirow{2}{*}{1.83} \\
\hline Stage 3 (Independence) & $-.07 * *$ & -.90 & .34 & 1.13 & \\
\hline Stage 3 (Mediation) & $-.48^{* *}$ & -6.59 & & \\
\hline
\end{tabular}

The above results are shown in [Fig. 2] as follows.

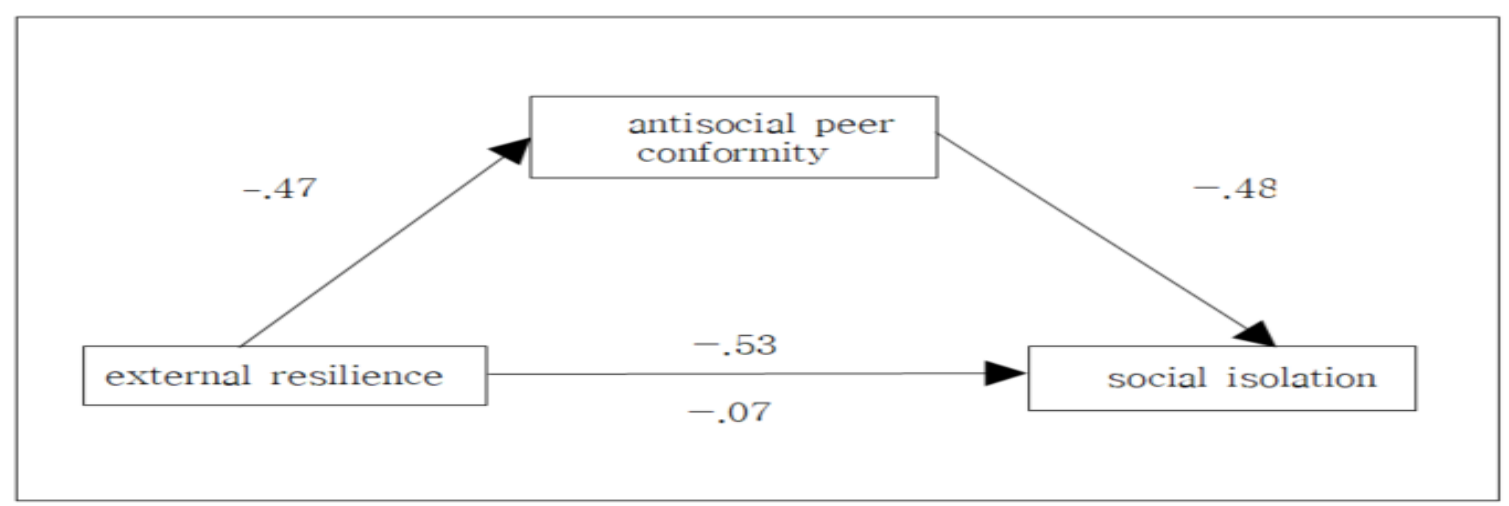

[Fig. 2] Mediating Effects of Antisocial Peer Conformity on the Relationship between External Resilience and Social Isolation of School Dropout Adolescents.

As a result of verifying the mediating effect of antisocial peer conformity on the relationship between external resilience and social isolation, which are psychosocial characteristics of school dropout adolescents, antisocial peer conformity partially mediated the relationship between external resilience and social isolation. This supports the hypothesis of this research which is based on the previous studies. 


\section{Conclusion}

\subsection{Discussion}

The purpose of this study was to examine the mediating effect of antisocial peer conformity on the relationship between external resilience and social isolation of adolescents who had stopped studying. A total of 395 subjects were selected. The data analysis was conducted using Windows SPSS 25.0 statistical program, frequency, percentage, average, and standard deviation as the main statistical methods, and correlation analysis between variables and Baron \& Kenny's three-step multiple regression analysis were conducted. The following are the main findings of the study. First, the external resilience of the students who had stopped studying showed negative correlations in the relationship between antisocial peer conformity and social isolation. Second, antisocial peer conformity had a mediating effect on the relationship between external resilience and social isolation of adolescents who had stopped studying. Finally, among the external resilience of the students who stopped studying, the protective factors of peers had the greatest effect on social isolation.

Based on the previous studies, the study intervened to explore the individual internal, individualenvironmental, and external variables on the premise that a social psychological approach to the phenomenon of dropout adolescents is needed. This study discussed the social psychological factors of the school dropout adolescents and suggested implications in terms of educational policies to prevent the students from stopping studying. First, the external resilience of the school dropout students showed negative correlations in the relationship between antisocial peer conformity and social isolation. These results are consistent with the results of meta-analysis by Jung Eun-joo and Jung Kyung-eun[15], which are external protective factors surrounding the school dropout adolescents, such as family, school (including peers), and social variables that promote resilience.

As for the protective factors of external resilience, the importance of peers, family, school, and community has been verified as external protective factors of educational ecosystem surrounding school dropout adolescents (including both inside and outside of school) in the developmental stage, so it is necessary to have an integrated perspective on the whole protective factors as well as one protective factor. In relation to the school dropout, the foundation of educational welfare policy should be a multilayered approach rather than a cross-sectional approach.

Second, antisocial peer conformity had a mediating effect on the relationship between external resilience and social isolation of school dropout adolescents. These results suggest that Hwang Insook[22], who showed that isolated students in the class showed a lower level of ability to view others or solve social problems than ordinary students, and the degree of social isolation experienced in adolescence is consistent with the study of Jung Su-jin and Lee Young-sun[23], who confirmed that adolescents play an important role in forming a social human network in their growth as adults.

The social isolation of the school dropout adolescents was confirmed as the main social psychological factor of school dropout, so it is required to develop the psychological social program (such as Academic Interruption Consideration System, alternative classrooms in schools, and out-of-school educational programs) that solves the social isolation and supports the adaptation of school life. This is an effort that must be continuously carried out as a preventive measure to support academic continuation of students at risk of academic discontinuation or as a follow-up to support return to school for adolescents with academic discontinuation.

Third, among the external resilience of school dropout adolescents, the protective factors of peers had the greatest effect on social isolation. Peer conformity of school dropout adolescents is a crisis in the growth of youth and an opportunity.

In order to understand antisocial behavior in adolescence, it is essential to understand peer influence, that is, 'peer conformity'. Peer conformity is a triggering and strengthening factor of delinquency, and 
early adolescents are more strongly associated with peer[24]. Especially, it can not be denied that peer friends have a direct influence on antisocial behavior in adolescence[25].

Peer conformity works in a relationship where peer-perceived pressure and personal ability to respond to such pressure interact. As such, the importance of peer influence increases in adolescence and peer pressure exerts a strong influence[26]. Deviated peer groups among peers have an effect on adolescents' participation in devious behaviors, that is, they become more devious as they get along with their peers who are engaged in devious behaviors[26]. However, in order to understand the effect of peer conformity, not only peer pressure but also personal factors that respond to external influences should be considered at the same time. These personal factors are the perception of the individual reflecting the sensitivity to peer influence, and the influence-response can be considered and the cognitive and behavioral characteristics are different according to the level of influence resistance[26].

\subsection{Conclusion}

In order to solve the antisocial peer conformity and social isolation of adolescents, it is important to form and maintain attachment relationships such as peer communication and trust of adolescents, and it is necessary to help form correct self-awareness. For this, it is necessary to provide affection and consideration to social supporters such as family, peers, and teachers to form positive relationships with each other. In order to form the right peer attachment, desirable relationship programs should be supported and operated[27]. In addition, it is necessary to develop integrated health education programs to eradicate emotional abuse and improve self-esteem and social support for the purpose of preventing internalization of problematic behaviors in adolescence[28]. Also, recommendations for improving the academic achievement of students and improving the school support system for reducing delinquency should be prepared[29].

Finally, peer counseling is actively proposed as a program to overcome the limitations of teachers and professional counselors among counseling resources for school dropout adolescents and to spread the results of counseling. The Solian Peer Counseling, which is currently being promoted by the Korea Youth Counseling and Welfare Institute, is a club program that helps students to adapt to school as well as prevent school violence. As of 2019, 482,933 peer counselors, 6,601 guidance teachers, and 9,012 operating schools are being established nationwide, which requires institutional activation to utilize them more actively in unit schools.

\subsection{Limitation and Recommendations}

This study contributes to the improvement of social psychological understanding of the school dropout adolescents and the need for systematic counseling, various education and activities for them. However, there are some limitations in this study. A total of 1,500 questionnaires were distributed to conduct surveys related to the purpose of the study, but 395 data were finally collected in the data analysis stage. In the future studies, it is necessary to increase the validity of the study through more data collection. Although the factors of school dropout are complexly related to various factors, this study has been conducted to identify social isolation as an individual internal variable, peer conformity as an individual-environmental variable, and resilience as an external variable. In future studies, it is necessary to study more diverse variables related to individuals, schools, and society in relation to the factors of school dropout. 


\section{References}

[1] S. H. Kim, B. H. Lee, The Assessment of Current Personality Education and the Way of Improvement for a Studies Drop-out Prevention of Youth, Journal of Education \& Culture, (2012), Vol.18, No.5, pp.143-164.

[2] https://kess.kedi.re.kr/index, Sept 10 (2020)

[3] J. S. Lee, Qualitative Meta-Analysis about the Change of Adolescences in the Process of Returning from the School Dropout, The Journal of the Korea Contents Society, (2017), Vol.17, No.12, pp.386-398.

[4] B. G. Kim, A. M. Cho, The types and characteristics of school dropouts : A latent class analysis approach, Korean Youth Research, (2013), Vol.24, No.3, pp.5-31.

[5] S. H. Kim, Social Psychology and Deviation of Korean Youth, Korea: Korea Social Research Center, http://www.kyobobook.co.kr/product/detailViewKor.laf?mallGb=KOR\&ejkGb=KOR\&barcode=9788991235458, (2007)

[6] A. Fall, G. Roberts, High school dropouts: Interactions between Social context, Self perception, School engagement, and Student dropout, Journal of Adolescence, (2012), Vol.35, No.4, pp.787-798.

[7] R. Awanh-Hashim, A. Kaur, M. Noman, The Interplay of Socio-psychological Factors on School engagement among Early Adolescence, Journal of Adolescence, (2015), Vol.45, December, pp.214-224.

[8] K. P. Cho, S. J. Kim, The Development of a Management Model for a Self-development Programs for Youth out of School, The Korea Journal of Youth Counseling, (2016), Vol.24, No.2, pp.387-416.

[9] C. K. Yun, S. R. Yoo, S. Y. Kim, J. Y. Lim, A. R. Um, E. H. Choi, A Longitudinal Survey and Support Plan for Dropouts, Korea: National Youth Policy Institute (NYPI) Research Report, (2013), pp.1-368.

[10] J. Y. Kim, J. S. Hong, The moderating Effects of Social Supports on the Relationship Between Self esteem and Achievement Motivation in Out of-School Youths, The Korea Journal of Youth Counseling, (2017), Vol.25, No.2, pp.393-412.

[11] Y. G. Yoon, C. N. Park, B. Y. Jeon, M. S. Jin, Survey on Youth and Alternative Education, Korea: Korea Education Development Institute Trust Research Report, (2002)

[12] B. Y. Gu, J. M. Yu, The neural network model of risk and protective factors on school drop out, Korean Journal of Health Psychology, (2003), Vol.8, No.1, pp.133-146.

[13] Y. T. Bae, Cause of School dropout and discrimination, The Korea Journal of Youth Counseling, (2003), Vol.11, No.2, pp.23-35.

[14] I. N. Sandler, S. A. Wolchick, T. S. Ayer, Resilience rather than recovery: a contextual framework on adaptation following bereavement, Death Study, (2008), Vol.32, No.1, pp.59-73.

[15] E. J. Jung, K. E. Jung, A Meta-analysis of the Variables Related to Resilience in Adolescence, Journal of School Social Work, (2019), Vol. 48, pp.243-273.

[16] H. R. Lee, H. Y. Cho, Development of the Resilience Scale of Korean Adolescents, The Korean Journal of School Psychology: Counseling and Psychotherapy, (2006), Vol.18, No.2, pp.353-571.

[17] B. H. Lee, The effects of the peer conformity on the cyberbullying of elementary school upper graders students: The moderating effects of self-esteem and moral implementation, Catholic University, Doctoral Dissertation, (2016)

[18] D. Haun, M. Tomasello, Conformity to peer pressure in preschool children, Child Development, (2011),Vol.82, No.6, pp.1759-1767.

[19] W. S. Im, Study on the Hazardous Environment of the Youth and Peer Pressure for It, Korean Journal of Youth Studies, (2008), Vol.15, No.7, pp.227-241.

[20] S. J. Jung, Y. S. Lee, Effect of the Father-Child Relationship on Social Problem Solving Cognized by Middle School Students : Mediating Effects of Social Isolation, The Korea Journal of Youth Counseling, (2017), Vol.25, No.1, pp.7394. 
[21] H. Y. Oh, S. H. Jee, H. J. Park, The Experience of School Dropouts who return to Academy, The Korea Journal of Youth Counseling, (2011), Vol.19, No.2, pp.125-154.

[22] I. S. Hwang, The Integrated Counseling Case Study of the Student Who Is Experiencing Social Isolation in Middle School, Dongguk University, Master's Thesis, (2015)

[23] J. S. Jung, Y. S. Lee, The Integrated Counseling Case Study of the Student Who Is Experiencing Social Isolation in Middle School, The Korea Journal of Youth Counseling, (2017), Vol.25, No.1, pp.73-94.

[24] Gardner. M, Steinberg. L, Peer influence on risk taking, risk preference, and risky decision making in adolescence and adulthood: an experimental study, Developmental Psychology, (2005), Vol.41, No.4, pp.625-635.

[25] H. L. Kim, J. H. Kim., I. J. Jung, The Effects of Peer Group on Adolescent Prosocial Behavior -Focusing on the Comparison between the Peer Influence Model and the Individual Characteristics Model-, Journal of the Korean Society of Child Welfare, (2011), No.36, pp.261 288.

[26] Y. J. Cho, O.B. Chung, Conformative Peer Bullying in Adolescents -Focusing on the Influence of Peer Conformity-, The Korean Journal of the Human Development, (2009), Vol.16, No.3, pp.91-111.

[27] Y. C. Kim, M. N. Lee, A Study on the Effect of Adolescent Self-Awareness on Peer Attachment, Internatio nal Journal of Beauty Science and Technology, (2018), Vol.2, No.1, pp.1-6.

[28] E. M. Kim, H.Y. Ahn, J. J. Woo, Self-Esteem, Social Support of Adolescents, International Journal of IT-based Public Health Management, (2018), Vol.5, No.2, pp.1-6.

[29] E. J. Kim, Effect of relationships with parents, friends, and self-esteem on academic performance and delinquency of middle school students, International Journal of Child Warfare Promotion and Management, (2018), Vol.2, No.2, pp.7580. 